\title{
Púrpura trombocitopênica idiopática em crianças: uma revisão narrativa
}

\author{
Idiopathic thrombocytopenic purpura in children: a narrative review \\ Púrpura trombocitopénica idiopática en niños: una revisión narrativa
}

\author{
Márilsi das Dores Queiroz \\ ORCID: https://orcid.org/0000-0002-0703-0152 \\ Universidade do Estado de Mato Grosso, Brasil \\ E-mail:marydqueiroz_@hotmail.com \\ Ariele Assunção Ramos de Souza \\ ORCID: https://orcid.org/0000-0003-2734-1190 \\ Universidade do Estado de Mato Grosso, Brasil \\ E-mail: ramos_ariele@hotmail.com \\ Aline Cristina Araújo Alcântara Rocha \\ ORCID: https://orcid.org/0000-0002-6689-5025 \\ Universidade do Estado de Mato Grosso, Brasil \\ E-mail: aline.cristina@unemat.br \\ Maria das Dores dos Santos \\ ORCID: https://orcid.org/0000-0002-3005-9324 \\ Universidade do Estado de Mato Grosso, Brasil \\ E-mail:maria.doracaceres@gmail.com \\ Danyella Rodrigues de Almeida \\ ORCID: https://orcid.org/0000-0003-1181-9321 \\ Universidade do Estado de Mato Grosso, Brasil \\ E-mail: dannypirelli@hotmail.com
}

\section{Resumo}

A Púrpura Trombocitopênica Idiopática é caracterizada pela diminuição do número de plaquetas circulantes, considerada autoimune e beningna, podendo ser classificada de acordo com o diagnóstico, idade e duração da doença. Objetivou-se realizar revisão da literateratura cientifica sobre a ocorrencia da pupura trombocotopênica idiopática em crianças e as possiveis intervenções de enfermagem. Trata-se de um estudo qualitativo de revisão narrativa de carater exploratório realizado em diferentes bases de dados eletrônicas. Analisou-se que as pesquisas sobre a doença existe questões controversas sobre o diagnóstico, tratamento e acompanhamento adequado para os portadores da patologia. Desta forma é necessario que mais estudo sejam realizados com maior profundidade sobre acerca do assunto, pensando no tratamento e no aumento da expectativa de vida dos portadores dessa doença.

Palavras- chave: Púrpura; Púrpura trombocitopênica; Sistemas sanguíneo e imunológico; Cuidados de enfermagem.

\begin{abstract}
Idiopathic Thrombocytopenic Purpura is characterized by a decrease in the number of circulating platelets, considered autoimmune and benign, and can be classified according to the diagnosis, age and duration of the disease. The objective was to review the scientific literature on the occurrence of idiopathic thrombocotopenic purpura in children and possible nursing interventions. This is a qualitative exploratory narrative review study carried out in different electronic databases. It was analyzed that research on the disease exists controversial issues about the diagnosis, treatment and adequate follow-up for patients with the pathology. In this way, it is necessary that more studies are carried out in greater depth on the subject, thinking about the treatment and increasing the life expectancy of patients with this disease.
\end{abstract}

Keywords: Purple; Thrombocytopenic purpura; Blood and immune systems; Nursing care.

\section{Resumen}

La Púrpura Trombocitopénica Idiopática se caracteriza por una disminución en el número de plaquetas circulantes, considerada autoinmune y benigna, y se puede clasificar según el diagnóstico, la edad y la duración de la enfermedad. El objetivo fue revisar la literatura científica sobre la aparición de púrpura trombocotopénica idiopática en niños y posibles intervenciones de enfermería. Se trata de un estudio cualitativo de revisión narrativa exploratoria realizado en diferentes bases de datos electrónicas. Se analizó que la investigación sobre la enfermedad tiene temas controvertidos sobre el diagnóstico, tratamiento y seguimiento adecuado de los pacientes con la patología. De esta forma, es necesario que se realicen más estudios con mayor profundidad sobre el tema, pensando en el tratamiento y aumentando la esperanza de vida de los pacientes con esta enfermedad.

Palabras-clave: Púrpura; Púrpura trombocitopénica; Sangre y sistemas inmunes; Cuidado de enfermera. 


\section{Introdução}

Púrpura Trombocitopênica Idiopática (PTI), é uma doença auto imune tendo como característica a baixa contagem de plaquetas, proveniente da destruição de plaquetas afetadaspor anticorpos no sistema reticuloendotelial, podendo afetar todas as faixas etárias e ambosos sexos (Provan et al.,2010). Devido essas caracteristicas a manifestação clinica mais comum dessa patologia é o sangramento (Aguiar, Mantovanelli, \& Freitas, 2021 ).

A PTI pode ser classificada em duas formas: a púrpura trombocitopênica aguda, mais frequente em crianças jovens (2 a 6 anos), acompanhada de alguma doença viral; e também, a púrpura trombocitopênica crônica, quando persiste por um período acima de seis meses (Shitsuka et al., 2017).

A PTI infantil é caracterizada como uma doença benigna e autolimitada que afeta tanto crianças do sexo femenino quanto do sexo masculino e possui uma estimativa de incidência de aproximadamente 1,9 a 6,4 casos para cada 100.000 por ano(Kuhne et al., 2011).

Na PTI complicações hemorrágicas graves são raras, e apenas a menoria das crianças desenvolvem a forma crônica da doença, em adultos a PTI possui predominância no sexo feminino, quanto em adolescentes a doença ainda possui as características clínicas e resultados mal definidos, a falta de dados deixa o tratamento médico para a PTI de um adolescente baseado apenas em sua experiência pessoal e suposições educadas para orientação ( Kuhne et al., 2011).

Kuhne et al. (2011), afirmam que as crianças podem desenvolver PTI aguda após doenças virais específicas tais como varicela ou HIV, ou como evento adverso pós vacinal, especialmente após a administração de vacinas virais como a Tríplice Viral (Sarampo, Rubéola e Caxumba), no entanto esses casos representam uma minoria, e também caracteriza a PTI aguda como sendo um início abrupto de diátese hemorrágica em uma criança saudável. Estudos recentes trazem que alguns pacientes receberam o diagnóstico de Purpura Trombocitopênica Imune Secundária à infecção Pelo novo Coronavírus SARS-CoV2( Rocha, 2020).

Para Delgado, Viana e Fernandes(2009), a ocorrência das hemorragias, na PTI depende da gravidade de trombocitopenia e da função plaquetária, podendo surgir petéquias hematomas e sangramentos das mucosas e raramente podem ocorrer hemorragias intracranianas e internas.

Em se tratando do diagnóstico da PTI, o mesmo é realizado por exclusão onde se analisa as condições clinicas como: sangramentos isolados e manifestações sistêmicas, e no exame físico avalia-se o aumento do tamanho do fígado e do baço, para o tratamento da doença em crianças a mesma deve possuir a enfermidade por um tempo superior a 12 meses , sendo recomendável a esplenectomia (Santana et al.,2013).

A escolha da tematica se deu pelo motivo da PTI infantil ser uma doença pouco conhecida, por isso definida como idiopática, sobretudo pelo desconhecimento dos enfermeiros, acadêmicos da saúde e os próprios portadores da doença, e acompanhamento de um caso famíliar, e a dificuldade em entender o desenvolvimento e os desdobramentos clínicose terapêuticos da PTI, dando ensejo assim a esta pesquisa.

O conhecimento sobre as características da púrpura trombocitopênica idiopática pela equipe de enfermagem contribuirá de forma significativa para garantir assistência de qualidade prestado no cuidado a criança portadora desta patologia, uma vez que contribui para o planejamento do cuidado, elaboração de protocolos de atendimento e também de manuais de orientação para os profissionais da saúde e para familiares.

Desse modo este estudo teve como objetivo realizar uma revisão da literatura cinetifica sobre a ocorrencia da Purpura Trombocitopênia Idiopatica( PPI) em crianças e as possiveis intervenções de enfermagem. 


\section{Metodologia}

Trata-se de um estudo qualitativo de revisão narrativa de caráter exploratório,realizada em diferentes bases de dados eletrônicos utilizando descritores catalogados no Descritor em Ciências da Saúde(DeCS) e utilizando os operadores booleanos “AND" e "OR", além da utilização das aspas a fim de facilitar a busca aos manuscritos.

A revisão da literatura consiste na construção do conhecimento científico, através desse processo surgem novas teorias e também são reconhecidas lacunas e oportunidades para o surgimento de pesquisas num determinado assunto(Botelho, Cunha \& Macedo 2011). Para Bernardo, Nobre e Jatene (2004) a revisão narrativa é utilizada para descrever o estado da arte de um assunto específico, sob o ponto de vista teórico ou contextual, esse tipo de revisão não fornece a metodologia para a busca das referências, nem as fontes de informação utilizadas, ou os critérios usados na avaliação e seleção dos trabalhos.

Esta pesquisa bibliográfica ocorreu no portal da Biblioteca Virtual em Saúde (BVS), Literatura Latino Americana e do Caribe em Ciências da Saúde (LILACS), Biblioteca Scientific Electronic Library online (Scielo), Google Acadêmico, manuais eletrônicos do Ministério da Saúde( MS) e livros. As buscas foram feitas utilizando as palavras-chaves: Púrpura ;Púrpura Trombocitopênica; Sistemas Sanguíneo e Imunológico; Cuidados de enfermagem, e suas respectivas traduções em inglês: Purple; Thrombocytopenic Purpura; Blood and Immune Systems; Nursing care, utilizando-se o operador booleano "AND” e “OR” e aspas a fim de facilitar as buscas aos manuscritos. No total foram encontradas 47 produções bibliográficas sendo elas: 25 artigos científicos, 20 livros e 2 Manuais do Ministério da Saúde, foram selecionados 25 publicações para o desenvolvimento deste estudo.

Foram incluídos neste estudo textos completos sobre Púrpura Trombocitopênica emcrianças publicados no período de 2003 a 2016, disponíveis em português e inglês de acordocom faixa etária de idade das crianças. Foram excluídos artigos que não apresentassem a disponibilidade de texto completo, e os que não discutem sobre o tema proposto. Após leitura e análise do material encontrado, foram criadas categorias visando organizar a descrição das informações encontradas através de três categorias sendo estas: patogenia, Purpura Trombocitopênia Idiopática, Processo de enfermagem.

\section{Resultados e Discussão}

\subsection{Categoria 1: Patogenia}

Nascimento et al. (2016), trazem que o tecido sanguíneo é constituído por uma parte líquido o " plasma” e outra composta por parte "sólida", as células ou elementos figurados, subdividem em glóbulos brancos (leucócitos) e glóbulos vermelhos (hemácias ou eritrócitos) e as plaquetas (trombócitos), os leucócitos e hemácias são as células de defesas e as plaquetas responsáveis pela coagulação sanguínea.

Os leucócitos exercem diversas funções de defesa uma das primeirasbarreiras contra infecções, os mesmos percorrem o corpo e atravessa a diapedese, a parede das vênulas e capilares se concentra nos tecidos afetados por microrganismos, onde exercem suas funções defensivas (Castro et al., 2006).

De acordo com Guyton e Hall (2011), as hemácias possuem funções de transportar o oxigênio, ligando a hemoglobina dos eritrócitos e gás carbônico ligado a hemoglobina e a outras proteínas dos eritrócitos.

As plaquetas, também denominadas de trombócitos, são pequenos fragmentos citoplasmáticos anucleados, discoides, derivados de megacariocitos da medula óssea e contem no citoplasma várias proteínas, citocinas e fatores bioativos que estão envolvidos com a regulação dos aspectos básicos da reparação tecidual, além da coagulação sanguínea(Voltarelli et al., 2010).

Segundo Castro et al. (2006), as plaquetas estão diretamente envolvidas emdiversas patologias importantes, sejam síndromes ou quadros trombóticos graves como a trombose artéria. Roitt e Rabson (2003) descrevem algumas alterações no sistema plaquetário, dentre elas a trombocitose caracterizado pela quantidade elevada de plaquetas no sangue que geralmente 
indica inflamação ou trauma.

A sobrevivência normal das plaquetas é de 7 a 10 dias, mas na PTI diminui para poucas horas, a quantidade de plaquetas é definida de acordo com o equilíbrio entre a produçãoe destruição plaquetária, em pacientes portadores de pupura tem um aumento da destruição plaquetária, sua produção também pode estar diminuída (Provan et al., 2010).

Pavanelli e Spitzner (2011) descrevem que a trombocitopenia ou plaquetopenia é um fenômeno onde ocorre a diminuição do número de plaquetas circulantes (inferior a $150.000 / \mathrm{mm}$ ), podendo se expressar por tempo de sangramento prolongado. Descreve ainda que:

A trombocitopenia pode surgir devido à produção insuficiente de plaquetas,sequestro esplênico, destruição aumentada, utilização aumentada ou diluição das plaquetas. A trombocitopenia grave, independente da etiologia, resulta em um padrão típico de sangramento cutâneo na forma de petéquias múltiplas, geralmentemais evidentes na extremidade inferior das pernas e pequenas equimoses dispersasem locais de trauma menor; sangramento da mucosa (epistaxe, trato GI, trato GUe sangramento vaginal) e sangramento excessivo após cirurgia. O sangramento grave no trato GI e no SNC pode pôr em risco a vida. Entretanto, a trombocitopenia não causa sangramento maciço nos tecidos (por exemplo, hematomas viscerais profundos ou hemartroses), que é característico de sangramento secundário à deficiência de fatores de coagulação plasmática (Pavanelli \& Spitzner 2011. p.328).

A destruição plaquetária acelerada é a causa mais comum de trombocitopenia, e podem resultar de defeitos intracorpusculares, comum em forma hereditária, e anormalidades extracorpulares, causadas por processos imunológicos (trombocitopenias autoimune ou aloimune) e não imunológicos (Barros, 2013).

Inúmeras doenças podem causar a redução no número de plaquetas, entretanto muitas vezes não se identifica uma causa específica. Segundo Rezende(2010) as principais razõesque produzem uma diminuição na quantidade de plaquetas são a produção insuficiente na medula óssea, sua alta destruição e sua diluição no sangue (Tabela1).

Tabela 1: Classificação das doenças associadas a plaquetopenia de acordo com mecanismofisiopatológico.

\begin{tabular}{|c|c|c|}
\hline \multicolumn{2}{|r|}{ Mecanismo } & \multirow[t]{2}{*}{ Doenças } \\
\hline 1. & Diminuição da produção & \\
\hline 1.1 & Hipoplasia de células precursoras & $\begin{array}{l}\text { Anemia aplastica, síndrome de wiskott-Aldrich, anomalia da May -Heglin, } \\
\text { síndrome de plaquetopenia com ausência de rádio, dano medularpor drogas } \\
\text { (cloranfenicol, cotrimoxazol,fenilbutazona, penicilamina), radiação, álcool, } \\
\text { infecção, produtos químicos (benzeno) }\end{array}$ \\
\hline \multicolumn{2}{|c|}{ 1.2 Substituição de tecido mieloide } & $\begin{array}{l}\text { Leucemias, mieloma múltiplo, tumores metastáticos } \\
\text { (próstata, mama, linfoma) }\end{array}$ \\
\hline
\end{tabular}

2. Aumento de destruição

2.1 Doenças imunes

2.2.Doenças não imunes

3 Trombopoise ineficaz

4 Problema de distribuição

5 Problema dilucional
Causa primaria: PTI, PTT (Alguns casos)

Causa Secundaria: Câncer (leucemia linfática crônica, linfoma, doenças autoimunes), drogas(fenacetina, sais de ouro, rifampicina, derivados da sulfa, penicilina, trimetropim, diazepam, valproatrode sódio, acetazolamida, tiazidicos, furosemida, clorpropramida, tolbutamida, digitoxina, metildopa, heparina,quinina/quinidina),infecções (mononucleose infecciosa, citomegalovirose, infecção pelo HIV)

Doenças caracterizada por anemia hemolítica microangiopatica e plaquetopenia (PTT, SHU,malária, CIVD, hemagioma cavernoso), septicemia, hemoglobinúria paroxística noturna.

Deficiência de folato ou vitamina B12

Mielodisplasias

Hiperesplenismo

Transfusão maciça

Fonte: Rezende (2010). 


\subsubsection{Sistema autoimune}

Para Hoffbrand e Mass (2013), a autoimunidade é a falha ocorrida em uma divisão funcional do sistema imunológico resultando em ações imunes contra as células e tecidos do próprio organismo, onde ocorre uma dificuldade na capacidade do sistema imunitário para distinguir entre moléculas do organismo e as que são estranhas.

Souza et al. (2010) descrevem que nas doenças autoimunes órgão-específicas e sistêmicas, nota-se perda da capacidade do sistema imunológico do indivíduo em reconhecer o que é próprio, daquilo que não é próprio.

A PTI resultante da formação dos anticorpos antiplaquetários e na destruição excessiva das plaquetas, é uma doença adquirida, geralmente benigna de causa desconhecida (idiopática), onde se reconhecem auto anticorpos, geralmente da classe $\mathrm{IgG}$, dirigidos a antígenos da membrana plaquetária(Castro et al., 2006).

Quando a plaqueta apresenta um anticorpo aderido à sua membrana, é reconhecida por macrófagos localizados no baço e no fígado, e em outras áreas do tecido reticular endotelial, onde são destruídas, induzindo a um menor tempo de vida média plaquetária, levando assim a menores contagens de plaquetas circulantes (Rezende, 2010).

Para Roitt e Rabson (2003), o baço é um órgão do tipo glandular e possui uma riqueza de células, considerado um importante órgão de defesa contra microrganismos que penetram no sangue circulante sendo o principal destruidor de eritrócitos desgastados pelo uso, o mesmo possui rapidez na resposta contra antígenos que invadem o sangue, sendo um importante filtro fagocitário e imunológico, além disso é um produtor de anticorpos.

Outro orgão de grande importãncia é o fígado, é nesse órgão que os nutrientes são absorvidos no trato digestivo e processados e armazenados para utilização de outros órgãos, além disso exercem outras funções como, armazenamento e liberação de glicose, metabolismo dos lipídeos, proteína do plasma, processamento de drogas e hormônios, destrói células sanguíneas desgastadas e bactérias, e a produção de proteínas plasmáticas, comoa albumina e outras proteínas carreadoras (Hoffbrand \& Mass, 2013).

\subsection{Categoria 2: Púrpura Trombocitopênia Idiopática em criança}

Segundo Provan et al.(2010) a PTI também conhecida por púrpura trombocitopênica imunonológica, autoimune, isoimune e doença de Werlhof. Perfaz o grupo de doenças de incidência rara na população, geralmente benigna e de causas desconhecidas, caracterizada por trombocitopenia.

Santana et al. (2013) descrevem a PTI como um distúrbio hematológico comum em crianças,o nome púrpura originouse mediante a presença de manchas roxas ou avermelhadas que aparecem na pele, e trombocitopênica decorrente ao processo de sangramento provocadopela diminuição do número de plaquetas e idiopática, pois a origem/causa não foi descoberta.

A PTI pode ocorrer em todas as faixas etárias e ambos os sexos, apresenta-se nas formas aguda e crônica, sendo que as crianças são mais acometidas, predominantemente, aforma aguda. Trata-se de uma doença de causa desconhecida que desenvolve em criançasentre 02 a 10 anos numa frequência de 4 a 8 casos a cada 100 mil crianças no mundo porano, apresentase de início súbito, ocorrendo geralmente durante a infância e, muitas vezes, se manifesta após uma infecção viral ou vacinação (Kühne et al., 2011).

A PTI infantil é caracterizada como uma doença benigna e autolimitada que afeta ambos os da mesma forma e tem uma estimativa de incidência de aproximadamente 1,9 a 6,4 casos para cada 100.000 por ano (Hoffbrand \& Moss, 2013). A maioria das criançasafetadas não necessita tratamento medicamentoso, sendo que $80 \%$ a $85 \%$ dos casos tem resolução espontânea da doença dentro dos primeiros seis meses de diagnóstico, cerca de $15 \%$ a $20 \%$ persistem trombocitopênicas durante seis meses ou mais, de forma crônica que se assemelha a doença nos adultos (Delgado et al., 2009). 


\subsubsection{Epidemiologia}

Segundo Brasil(2013), PTI é uma doença que atinge na maioria das vezes mulheres sem idade fértil, mas pode aparecer em qualquer idade e ambos os sexos. Guerra et al. (2011), estudando a plaquetopenia em um centro de hematologia em São Paulo, constatou que dos 1.057 casos (7\%) encaminhados por plaquetopenia, 670 casos $(63,4 \%)$ eram do sexofeminino, e as idades variavam entre 1 e 75 anos, e a PTI foi encontrada em 52\% dos casos,sendo mais frequente no sexo feminino, em crianças e adultos jovens.

Segundo Delgado, Viana e Fernandes (2009), a estimativa da incidência da PTI em crianças entre os 2-5 anos de idade, é de 5,5 em um total de 100.000, na população adulta a incidência é de pelo menos 2,15, as mulheres são mais atingidas do que os homens, em um total de 100.000 pessoas, em média 16,55 são do sexo feminino. Os etudos de Lorenzi (2015) traz que a PTI crônica na criança existe uma incidência aproximada de 0,46 por 100.000 crianças ao ano.

Os estudos epidemiológicos internacionais demontram que a incidência em adultos é de 1,6-2,7 casos por 100.000 pessoas/ano e uma prevalência de 9,5-23,6 casos por 100.000 pessoas, com preponderância no sexo feminino(Brasil, 2013).

No Japão os estudos mostram uma prevalência de 15,5 casos ao ano para cada 100.000 indivíduos (Delgado et al., 2009). Al-Mulla et al (2009), pesquisando a PTIna população infantil de Catar constatou dentre as crianças estudadas, $62 \%$ apresentavam PTI aguda e 38\% PTI crônica. Ao correlacionar com os estudos de Robb apud Al-Mulla (2009) observa-se que o índice de PTI crônica encontrado nas crianças no Catar maior do que a proporção esperada para crianças com menos de 15 anos de idade, 20\% do Kuwait, onde os casos agudos eram duas vezes mais comuns do que os casos crônicos.

Segundo Lorenzi (2015), a PTI na infância na maioria dos casos a doença é desencadeada por infeções virais e a maior parte das crianças afetadas não necessitam de tratamento medicamentoso e, $80 \%$ a 85\% dos casos têm resolução espontânea da doença, dentro dos primeiros 6 meses após o diagnóstico, no entanto, cerca de $15 \%$ a $20 \%$ das crianças persistem trombocitopênicas por um tempo superior a 6 meses, e desenvolvendo a forma crônica. (Bordin, Junior \& Covas, 2007).

A mortalidade por PTI é menos de $5 \%$ e ocorre por sangramentos, geralmente em sistema nervoso central ou trato gastrintestinal, em paciente refratário ao tratamento comcorticoide e à esplenectomia, com intensa trombocitopenia, e plaquetas abaixo de 10.000/L(Lorenzi, 2015).

\subsubsection{Fisiopatologia}

As plaquetas, também conhecidas por trombócitos são células do sangue formadas na medula óssea, um indivíduo saudável tem entre 150.000 e 400.000 plaquetas por $\mathrm{ml}$ de sangue, com a função de iniciar o processo de coagulação, agrupando em formato de rolha,objetivando o estancamento do sangramento, consequentemente ocasionando a reparação da lesão sem que ocorra maiores perdas sanguíneas (Al-Mulla et al., 2009).

Apesar da etiologia ser desconhecida, identificam-se auto anticorpos, frequentemente da classe IgG, conduzidas a antígenos da membrana plaquetária devido a plaqueta apresentarum anticorpo prendido à sua membrana, é reconhecido por macrófagos encontrados no baçoe em outras áreas de tecido reticulo endotelial, onde são destruídas, induzindo a um menor período de vida médio plaquetário e, por conseguinte, a diminuição da contagem deplaquetas circulantes (Bordin et al., 2007).

Segundo Kühne et al. (2013), a eliminação das plaquetas é ocasionada por anticorpos antiplaquetários, sendo imunológicos ou não imunológicos, pode-se afirmar a presença de anticorpos reativos que ataca as glicoproteínas da membrana plasmática.

Santana et al. (2013) descrevem que as plaquetas opsonizadas se fixam às células apresentadoras de antígenos macrófagos ou células dendríticas onde são fagocitadas e destruidas, as células que apresentam antígenos ampliam a resposta imune inicial expressando novos peptídeos na sua superfície e dando início ao desenvolvimento de clonesde células T CD4positivas, os receptores de imunoglobulina das células B que reconhecemos antígenos plaquetários são juntamente induzidos a proliferar e a sintetizar anticorpos antiglicoproteína. 


\subsubsection{Classificação}

Segundo Brasil (2013), a PTI pode ser classificada de acordo com a presença ou ausência de um distúrbio subjacente, primária ou secundária, e a faixa etária acometida, como infantil ou adulta e, de acordo com o tempo de evolução, aguda ou crônica.

A PTI aguda é auto limitativa, tem uma duração inferior a 6 meses, podendo atingir crianças com idade entre os 2 e 6 anos (sucedendo o pico mais alto aos 4 anos) efrequentemente aparece na sequência de uma doença viral, a crônica, ocorre com maisconstância em menores de 1 ano e maiores de 10 anos de idade, com maior prevalência no sexo feminino, sendo assim originadas pela produção de um auto-anticorpo (IgG) contra umantígeno plaquetário (Lorenzi, 2015).

Na tabela 2, Garanito (2009) descreve as diferenças entre a PTI aguda e crônica.

Tabela 2-Diferenças entre PTI aguda e crônica em pediatria.

\begin{tabular}{|c|c|c|}
\hline & AGUDA & CRÔNICA \\
\hline Incidência & $80 \%$ & $20 \%$ \\
\hline Sexo & $\mathrm{M}=\mathrm{F}$ & $3 \mathrm{~F}: 1 \mathrm{M}$ \\
\hline Início & 18 meses a 6 anos & Acima de 10 anos \\
\hline Plaquetopenia Inicial & $<10.000 / \mathrm{mm}$ & Moderada \\
\hline Quadro Clínico & BEG, petéquias e equimoses & Leve \\
\hline \multirow[t]{4}{*}{ Remissão espontânea } & $50 \%: 4-8$ semanas & $20 \%$ em 4 anos \\
\hline & \multicolumn{2}{|l|}{$66 \%: 3$ meses } \\
\hline & \multicolumn{2}{|l|}{$\begin{array}{l}76 \%: 6 \text { meses Dos } 24 \% \\
\text { restantes }=37 \% \text { recupera em até }\end{array}$} \\
\hline & 12 meses & \\
\hline
\end{tabular}

$\begin{array}{lrrr}\text { Antecedentes } & (2-4 & \text { semanasInfecção viral } & \text { Geralmente ausente } \\ \text { antes }) & \text { Vacina por vírus vivo atenuado }\end{array}$

Fonte: Garanito (2009).

A PTI primária é evidenciada por plaquetopenia isolada, sem reconhecimento do fator precipitante, embora o agente etiológico seja desconhecido, fatores, como mutações gênicas, drogas ou doenças infecciosas podem influenciar o fenótipo da doença, entre tanto a secundária acontece simultaneamente com um distúrbio subjacente responsável por distúrbios de função imune levando a trombocitopenia (Kühne et al., 2013).

\subsubsection{Sintomatologia}

Segundo Zago et al. (2013), ocorre o aparecimento súbito de púrpura e petéquias cutaneo mucusa difusa em criança previamente saudável, de modo geral, não apresentava outras alterações, em sua maioria, antecedente a doença verifica-se a ocorrência de infecção prévia viral nos dois meses precedentes, geralmente de vias aéreas superiores.

De acordo com Lorenzi (2015), as hemorragias características da doença podem ocorrer como petéquias e hematomas subcutâneos, hemorragia denominada seca, se as membranas mucosas não são envolvidas, ou hemorrágica molhada que inclui hemorragias nasais, sangramento de gengivas, hematúria, menorragia, ou sangramento gastrointestinal e trato urinário. Os sintomas surgem quando ocorre a queda no número de plaquetas que comprometem a coagulação do sangue, provocando sangramentos, estes ssangramentos são na pele e mucosas sob a forma de equimoses e petéquias (Zago et al., 2013). 
$\mathrm{Na}$ infância, pode suceder remissão espontânea da doença, o que não acontece com facilidade na vida adulta. A PTI aguda em criança deve - se ter cuidado com traumas duranteo período de plaquetopenia, principalmente quando esta é acumulada, na forma crônica,quando há paquetopenia acentuada com sintomas de sangramentos séricos, e risco de hemorragias do sistema nervoso central, também há indicação de hospitalização e transfusão de plaquetas (Hoffbrand et al., 2013; Zago et al., 2013).

Segundo estudo produzido por Kühne et al. (2013), Observou-se manifestações hemorrágicas com maior frequência em crianças com $91 \%$, e em pacientes adultos $69 \%$ apresentaram hemorragias, em se tratando de hemorragia intracraniana os valores se mostram insignificantes, ocorrendo em crianças $(0,6 \%) \mathrm{e}$ em adultos $(1,8 \%)$, as crianças com hemorragia intracraniana tinham a idade média de cinco anos e os adultos 60 anos.

\subsubsection{Diagnóstico}

De acordo com Alves et al. (2021) o diagnóstico da PTI pode ser realizado primeiramente através da história clínica, do exame físico e do hemograma completo para verificar se há redução no número de plaquetas, outros métodos diagnósticos é o esfregaço de sangue periférico e o método de exclusão.

Para o diagnóstico de PTI utiliza-se o método de exclusão, onde é avaliado as condições clínicas do paciente tais como: sintomas de sangramento isolado sem outras demonstrações sistêmicas, também realiz-se exame físico onde são analisados a ausência de hepatoesplenomegaliaou linfoadenomegalia, e contagem de células sanguíneas (plaquetopenia isolada $<100 \mathrm{x}$ 109/L) e o exame de esfregaço de sangue periférico (células vermelhas e brancas com morfologia normais) não indicam outra etiologia (Santana et al., 2013).

A utilização do exame de exclusão na PTI é de suma importância, uma vez que os métodos terapêuticos para o tratamento de PTI podem ser utilizados em outras doenças, taiscomo: Lúpus Eritematoso Sistêmico (LES), Anemia Hemofílica Auto Imune (AHAI) e em quadros de leucemias (Hoffbrand \& Moss, 2013).

Durante a avaliação do exame físico em criança acometida pela PTI , os individuos aparentemente são saudáveis, com ótimo estado de saúde, com ausência de febre e dor,perda de peso ou hipoatividade, as manifestação clínica encontrada durante a avaliação resume-se apenas na presença de petéquias e equimoses, outras manifestações como à presença de adenopatias, visceromegalias ou alterações no exame físico e laboratorial tais como: anemia, leucocitose ou leucopenia (Santana et al., 2013).

Considera-se importante a realização do mielograma, mediante este exame, torna-se possível a exclusão de outras doenças basicamente com as mesma características, exemplificando a: leucemia e da mielodisplasia, onde ocorre a diminuição de hemoglobina e a plaquetopenia (Rezende, 2010).

\subsubsection{Tratamento}

O tratamento de PTI é realizado por meio de corticoides e imunoglobulina intravenosa, permitindo controlar os sintomas e estimulando o aumento das plaquetas, diminuindo assim o risco de sangramento Hoffbrand et al., 2013; Zago et al., 2013.

O tratamento realizado na infãncia e adolescência com quadro agudo de PTI, ainda é motivo de discussão, pois não existe comprovação permanente no tratamento medicamentoso sobre o estudo criterioso, os argumentos que sustentam o estudo criterioso se encontra o caso de a maior parte das crianças restabelece por completo de umquadro agudo de PTI, independentemente da concretização de qualquer tratamento e de nãomostrar sangramentos relevantes mesmo com contagens plaquetárias inferior a 10.000/mm3. (Barros, 2013; Boquimpani et al., 2014).

Para Rezende (2010) o tratamento através de medicamentos elevam rapidamente a contagem das plaquetas, reduzindo os riscos de sangramentos graves, a observação criteriosa é uma opção terapêutica inicial para crianças com PTI aguda sem 
apresentação de sangramentos, são orientadas a restrição de algumas atividades como esportes de contato, uso de medicamento antiplaquetário tais como acetilsalicílico e anti-inflamtório não esteroides, tratamentos alternativos são os corticosteroides e as imunoglobulinas( Barros, 2013).

Segundo Brasil (2013), a amioria das crianças se recuperam espontaneamente da PTI eo tratamento medicamentoso é indicado somente na existência de trombocitopenia grave ou sangramentos que coloquem em risco a vida o paciente, não sendo recomendo tratamento com medicamentos quando o nível de plaquetas se encontram acima dos 30.000/ml, para pacientes com plaquetas inferior a 30.000/ml, a recomendação ou não do tratamento deve ser individualizado, avaliando-se caso a caso.

Do mesmo modo como nas crianças, o tratamento com drogas em adultos só é indicado quando há contagem de plaquetas muito baixa com possibilidade de sangramento grave, pacientes com plaquetas superior a 50.000/ml só necessitam de acompanhamento contínuo, semelhante aos das crianças, mais nos adulto não se espera uma resolução completa da doença, sendo assim, recomenda apenas impedir quedas abrupta do número das plaquetas. A esplenectomia pode ser sugerida em situações graves que duram mais de seis meses (Bordin et al.,2007).

Segundo Boquimpani et al. (2014), as drogas usadas são toxicas, e muitas são imunopressoras, sendo assim, o seu uso prolongado aumenta o risco de infecções por vírus, fungos e bactérias, além de deixar propício a outras doenças malignas, como linfomase alguns tumores de órgãos sólidos e leucemias.

Para Barros (2013) e Silva e Brando 2021, pessoas com contagem de plaquetas inferior a 30.000/ml, iniciam a terapia com corticóides (prednisona) orais são considerados a primeira linha de tratamento para a PTI, na dose de $1 \mathrm{mg} / \mathrm{kg}$ de peso corporal por dia, se a contagem das plaquetas estiver entre 10.000 a 30.000, sem hemorragias séricas, para trombocitopenias mais severas, menos de $10.000 / \mathrm{ml}$, e na presença de hemorragias séricas, a dose deverá ser iniciada por $2 \mathrm{mg} / \mathrm{kg} / \mathrm{dia}$.

Os corticoides devem ser mantidos pelo um periodo de três meses, de forma a permitir uma remissão espontânea, se após este período altas doses forem requeridas para controlar a doença, muitas especialistas recomendam a ressecção do baço, o principal órgão de destruição das plaquetas, através de esplenectomia, o tratamentos prolongados com corticosteroides causam graves efeitos colaterais e toxicidade, diabetes, psicoses, infecções por agentes oportunistas, erosões e úlceras gástricas e supressão das glândulas supra-renais (Boquimpani et al., 2014).

Doentes com contagem de plaquetas superior a 30.000, geralmente apresentam poucos sintomas, mantendo-se estáveis durante anos e não requerem esplenectomia ou terapêutica crônica, em presença de situações associadas com risco de hemorragias como extração dentária, cirurgia eletiva, breves cursos terapêuticos de prednisona podem ser usados para elevar a contagem de plaquetas, antes da cirurgia (Lorenzi, 2015).

Para Barros (2013), se a remoção cirúrgica do baço é necessária, muitas precauções deveram ser tomadas, se a doença responder a prednisona, uma dose alta deverá ser administrada no pré-operatório, para aumentar a contagem de plaquetas acima de 50.000/ml, infusões de imunoglobulinas endovenosas podem ser usadas, se o paciente não responde a nenhuma das medidas tomadas, deverá ser realizada uma transfusão de plaquetas na dose de 2 unidades $/ 10 \mathrm{~kg}$ de peso corporal e deve ser administrada na altura da intubação para a anestesia.

Pessoas que não possuem o baço ficam em risco para o desenvolvimento de infecções bacterianas fatais, causadas por certas bactérias, dentre elas os pneumococos, meningococos, hemophillus influenzae, por esse motivo se indica a vacinação contra esses agentes, especialmente a antipneumocócica (Lorenzi, 2015).

Segundo Pavanelli e Spitzner (2011), após a esplenectomia 50\% dos pacientes tem uma completa e permanente remissão, e em 30\% a contagem de plaquetas sobe para valores seguras (30.000 - 150.000), que não necessitam de terapêutica, $20 \%$ tem contagem de plaquetas entre 10.000 a $30.000 / \mathrm{ml}$, apresenta poucos sintomas e raramente aparecem complicações a longo prazo, em geral não necessitam de terapêutica crônica.

De acordo com Barros (2013), se portadores de PTI necessitarem de uma cirurgia deemergência, como apendicite aguda 
ou traumas, transfusões de plaquetas são necessárias, já que elevam imediatamente, embora a contagem regresse aos valores prétransfusão cerca de24 horas depois.

\subsection{Categoria 3: Processo de enfermagem}

Segundo Andrade e Viera (2005), o processo de enfermagem (PE) é um instrumento metodológico que permite identificar, compreender e descrever ao processo de saúde/doençado paciente acometido por determinada patologia.

O PE trata-se de uma metodologia que tem como objetivo colaborar com a troca de informações entre enfermeiros, equipe e instituições, proporciona o enfermeiro desempenha a assistência de enfermagem centrada nos cuidados individual (Alfaro-Lefevre, 2005).

Para Alfaro-Lefevre( 2005) a "Sistematização da Assistência de Enfermagem”( SAE) é um conjunto de instrumento que instrumentalizam o enfermeiro, analogamente o PE visa orientar a pratica assistencial de enfermagem bem como a sua documentação". A SAE possui objetivo nortear o trabalho do enfermeiro, através da organização da assistência, planejando, executando e avaliando os cuidados de enfermagem de uma forma integral (Barros, 2012).

Segundo Andrade e Vieira (2005), afirma que para implementar a SAE seleciona-se uma teoria de enfermagem que direcione as demais etapas do PE, devendo ser feita de maneira reflexiva e cuidadosa e os enfermeiros necessitam compreender quais são os conceitos das teorias de enfermagem e relacioná-los com aqueles que emergem de discussões com a equipe e com a população do ambiente no qual a SAE seinsere.

O PE possibilita diferenciar o cuidado, servindo de base para as intervenções, objetivando identificar as dificuldades existentes, conseguidos a partir da apreciação das informações colhidas na investigação e fundamentação para o planeamento do cuidado, isto é elaborar um diagnóstico de enfermagem demanda análise dados clínicos, possibilitando ao profissional atomada de decisões quanto aos resultados almejados (Nóbrega et al., 2011).

Entre os múltiplos sistemas de classificação desenvolvidos para implementação do PE, destaca-se a taxonomia da NANDA Internacional, a Classificação de Intervenções de Enfermagem (NIC), a Classificação de Resultados Esperados (NOC) e a Classificação Internacional para a Prática de Enfermagem (CIPEß) (Nobrega et al., 2011). Por conseguinte sistematizar e organizar a assistência de enfermagem é de fundamental importância, diante desta perspectiva utilizamos a taxonomia da NANDA.

\section{Considerações Finais}

A Púrpura Trombocitopênica Idiopática em crianças é uma doença auto imune onde ocorre a baixa contagem das plaquetas, sua etiológia ainda é desconhecida, a doença acomete todas as faixas etárias e ambos os sexos, afetando principalmente crianças, sendo classificada como aguda ou crônica.

Entretanto nota-se a ausência de publicações com informações recentes, que tracem os principais diagnósticos e cuidados de enfermagem, visto que a maioria das publicações encontradas os estudos são direcionados a fisiopatologia, não trazem orientações para a equipe de enfermagem em como lidar com possíveis alterações evidenciadas através dos sinais e sintomas.

Como recomendações espera-se que este estudo desperte interesse das entidades cientificas, para realizar estudos aprofundados acerca do assunto. Sugere-se ainda que estas novas pesquisas sejam direcionadas acerca dos principais cuidados de enfermagem aos portadores dessa patologia. 


\section{Referências}

Aguiar, J. B.Jean., Mantovanelli, L. S., \& Freitas V. L.S.( 2021). A importância do farmacêutico bioquímico no diagnóstico da púrpura trombocitopênica idiopática (PTI). Research, Society and Development, (10) 9, 1-7. doi: http://dx.doi.org/10.33448/rsd-v10i9.18308

Alfaro-Lefevre, R. (2005). Aplicação do processo de enfermagem: promoção do cuidado colaborativo. Porto Alegre: Artmed.

Al-Mulla, N., Bener, A., Amer, A., \& Laban, M.A. (2009). Púrpura trombocitopênica idiopática na infância: estudo de base populacional no Catar. Jornal de Pediatria, (85) 3, 269-272. Fap UNIFESP (SciELO). doi.org/10.1590/s0021-75572009000300014.

Alves, A. K. R., Silva, B. B. L., Silva, T. L., Matos, L. K.B. L., \& Mello, G. W.S. (2021). Púrpura trombocitopênica idiopática: uma doença subdiagnosticada. Revista SUSTINERE, (9)1, 50-64. doi: http://dx.doi org/10.12957/sustinere.2021.51295.

Andrade, J. S., \& Vieira, M. J. (2005) Prática assistencial de enfermagem: problemas, perspectivas e necessidade de sistematização. Revista Brasileira de Enfermagem, Brasília, (58) 3, 261-265. doi.org/10.1590/s0034-71672005000300002.

Barros, F. E. V. (2013). Sistema apoptótico plaquetário em diferentes graus de plaquetopenia da Trombocitopenia Imune, São Paulo, 2013.

Bernardo, W.M., Nobre, M.R.C., \& Jatene, F. B. (2004). A prática clínica baseada em evidências: parte II - buscando as evidências em fontes de informação. Revista da Associação Médica Brasileira, São Paulo, 50(1), 104-108, doi.org/10. 1590/s0104-42302004000100045.

Boquimpani, C., Máximo, C., Duarte, M. E., Silveira, S., \& Madeira, T. (2014). Protocolos de tratamento: hematologia e hemoterapia. Rio de Janeiro: Instituto Estadual de Hematologia Arthur de Siqueira Cavalcanti, 273.

Bordin, J. O., Junior, D.M.L., \& Covas, D.T. (2007). Tratado de Hemoterapia Fundamentos e Prática. São Paulo: Atheneu.

Botelho, L. L. R., Cunha, C.C. A., \& Macedo, M. (2011). O método da revisão integrativa nos estudos organizacionais. Gestão e sociedade, (5) 11, 121-136. doi: https://doi.org/10.21171/ges.v5i11.1220

Brasil. Ministério da saúde. (2013). Protocolo clínico e diretrizes terapêuticas da púrpura trombocitopênica idiopática. Portaria SAS/MS n ${ }^{\circ} 1.316$.

Recuperado de file:///C:/Users/bruni/OneDrive/Documentos/TCC/8\%20\%20Protocolo\%20clínico\%20e\%20diretrizes\%20terapêuticas\%20da\%20PTI.pdf.

Castro, H. C., Ferreira, B.L.A., Nagashima, T., Shueler, A., Rueff, C., Camisasca, D., Moreira, G., Scovino, G., Borges, L., Leal, M., Filgueira, M., Paschoal, P., Bernardo, V., Bourguinhon, S., \& Rodrigues, D.O.S. (2006). Plaquetas: ainda um alvo terapêutico. Jornal Brasileiro de Patologia e Medicina Laboratorial, 42(5), 321-332. doi: 10.1590/S1676-24442006000500004.

Delgado, R. B., Viana, M. B., \& Fernandes, R. A. F. (2009). Púrpura trombocitopênica imune da criança: experiência de 12 anos em uma única instituição brasileira. Revista Brasileira de Hematologia e Hemoterapia, (31) 1, 29-36.

Garanito, M.P. (Org.). (2009). Púrpura trombocitopênica imunológica. Sociedade de Pediatria de São Paulo, (50) 50, 1-14. Recuperado de http://www.spsp.org.br/site/asp/recomendacoes/Rec_62_Dermato.pdf.

Guerra, J. C. C., Kanayama, R.H., Nozawa, S.T., Loshida, M.R., Takiri, I.Y.,Lazaro, R.J., Hamerschlak, n., Rosenfeld, L.G.M., Guerra, C.C.C., \& Bacal, N.S.( 2011). Plaquetopenias: diagnóstico usando citometria de fluxo e anticorpos antiplaquetas. Einstei, (9)2, 130-140. doi.org/10.1590/S1679$45082011 \mathrm{AO} 1846$.

Guyton, A.C. Tratado de Fisiologia Médica. (2011). Rio de Janeiro: Guanabara Koogan.

Hoffbrand, A.V., \& Moss, P.A.H. Fundamentos em hematologia. Porto Alegre: Artmed, 2013.

Kuhne, T., Berchtold W., Michaels, L.A., Wu, R., Donato,H., Espina B., Tamary, H., Rodeghiero, F., Chitlur, M., Rischewski, J., \& Imbach, P.( 2011). Trombocitopenia imune recentemente diagnosticada em crianças e adultos: um registro observacional. Hematológica, 96(12), 1831-7. doi: 10.3324/hematol.2011.050799.

Lorenzi, T. F. (2015). Manual de hematologia: Propedêutica e clínica. Rio de Janeiro: Guanabara.

Nascimento, C. A. D., Charmênia, M.B.C., Lopes, K.A.M., Bushatsky, M., Batista A.F. (2016). Leucemia Mieloide Aguda (LMA): as condições psicológicas do paciente adulto. Psicologia em Revista, Belo Horizonte, 22(2), 336-355. doi: 10.5752/P.1678-9523.2016V22N2P336.

Nóbrega, R. V., Nóbrega, M. M. L., \& Silva, K. L. (2011). Diagnósticos, resultados e intervenções de enfermagem para crianças na Clínica Pediátrica de um hospital escola. Revista Brasileira de Enfermagem, (64)3, 501-510. doi.org/10.1590/S0034-71672011000300014.

Pavanelli, M. F., \& Spitzner, F. L. (2011). Trombocitopenia Induzida por Heparina: Revisão da Literatura. Unopar Cient Ciênc Biol Saúde, (13) 1, 325-331. doi.org/10.17921/2447-8938.2011v0n0p\%25p.

Provan, D., Stasi, R., Newland A.C., Blanchette, V. S., Maggs, P.B., Bussel, J.B., Chong, B. H., Cines, D. B., Gernsheimer, T.B., Godeau, B., Grainger, J., Greer, I., Hunt, B.J., Imbach, P.A., Lyons, G., McMillan, R., Rodeghiero, F., Sanz, M.A., Tarantino, M., Watson, S., Young, J., \& Kuter, D.J. (2010). International consensus report on the investigation and management of primary immune thrombocytopenia. The American Society Of Hematology, Blood, (115)2, 168-186.

Rezende, S. M. (2010). Distúrbios da hemostasia: doenças hemorrágicas. Revista Médica de Minas Gerais, (20) 4, $534-553$.

Rocha, A. Q. A. (2020). Púrpura Trombocitopênica Imune Secundária à Infecção por Coronavírus SARS-COV2: Relato de caso. Hematology, Transfusion and Cell Therapy. (42) 84. doi: https://doi.org/10.1016/j.htct.2020.10.142

Roitt, I. M., \& Rabson, A. (2003). Imunologia Básica. Rio de Janeiro: Guanabara. 
Research, Society and Development, v. 11, n. 2, e35711225734, 2022 (CC BY 4.0) | ISSN 2525-3409 | DOI: http://dx.doi.org/10.33448/rsd-v11i2.25734

Santana, L. M., Neves, T., Fenili, A.C., Borba, L. G., Kirst, D., Fetter, F., Taniguchi, A.N., Sabarroz, V., \& Michalow M.B. (2013). Trombocitopenia autoimune em crianças: revisão das recomendações do último consenso. Boletim Científico de Pediatria, (2)3, 77-82. Recuperado de http://www.sprs.com.br/sprs2013/bancoimg/140324183300bcped_13_03_03.pdf.

Shitsuka, C., Bispo, L. B., Oliveira, D.G., Gonzalez, R. A.B., Murisi, I.P. (2017). Cuidados bucais em pacientes com púrpura trombocitopênica idiopática Oral care in idiopathic thrombocytopenic purpura patients. Research, Society and Development, (5)4, 314-321.

Silva, C. L., \& Grando, A.C. (2021). Complicações da púrpura trombocitopênica idiopática na gravidez: uma revisão da literatura. J Bras Patol Med Lab. 57, $1-9$

Souza, A. W. S., Junior, D.M., Araújo, J.A.P., Catelan, T.T.T., Cruvine, W.M., \& Andrade, Silva, N.P. (2010). Sistema Imunitário - Parte III O delicado equilíbrio do sistema imunológico entre os pólos de tolerância e autoimunidade. Rev Bras Reumatol, (50) 6, 665-94. Recuperado de http://www.scielo.br/pdf/rbr/v50n6/v50n6a07.pdf

Voltarelli, J. C., Moraes, D.A., Ribeiro, A. A. F., Oliveira, M. C., Rodrigues, M., Brum, D.G., Bareira, A. A., \& Hamerschlak, N. (2010). Consenso brasileiro para transplante de células-tronco hematopoéticas para tratamento de doenças autoimunes. Revista Brasileira de Hematologia e Hemoterapia, (32)1, 125-135. Recuperado de http://www.scielo.br/pdf/rbhh/v32s1/aop23010

Zago, M. A., Falcão, R. P., \& Pasquini, R. (2013). Tratado de Hematologia. Editora: Atheneu. 